\title{
The Investigation and Analysis of the Damage of Buildings in Coastal Towns and Villages by Typhoon
}

\author{
Linsheng HUO \\ Faculty of Infrastructure Engineering \\ Dalian University of Technology \\ Dalian, China \\ e-mail: 1shuo@dlut.edu.cn \\ Gang LI \\ Faculty of Infrastructure Engineering \\ Dalian University of Technology \\ Dalian, China \\ e-mail: gli@dlut.edu.cn
}

\author{
Yinkun WANG \\ Faculty of Infrastructure Engineering \\ Dalian University of Technology \\ Dalian, China \\ e-mail: wangyinkun1222@163.com
}

\author{
Hongnan LI \\ Faculty of Infrastructure Engineering \\ Dalian University of Technology \\ Dalian, China \\ e-mail:hnli@dlut.edu.cn
}

\begin{abstract}
Typhoon can cause great destroy to the buildings of the towns and villages in the coastal areas. It is essential to investigate the damage and wind resistance performance of buildings in coast areas. This paper investigated some common characteristics of the houses destroyed by typhoon, including grey tile roofs, poor integrity, small stiffness, structure aging, weak connection and without longitudinal resistance system. By further analysis, it is found that the destruction of towns and villages houses by typhoon mostly began from the roof, then the breakdown of walls and even the collapse of the overall house. The paper also summarizes the causes and main structural characteristics of the destroyed houses in towns and villages of coastal zones, and points out some problems exposed under the construction of these towns and villages buildings. Finally, some suggestions are proposed in this paper, which are beneficial to wind resistance of the buildings on the aspects of planning construction and construction measures.
\end{abstract}

Keywords-typhoon; coastal towns and villages; the destruction of the roof; the performance of wind resistance; construction measu res

\section{INTRODUCTION}

The southeast coastal areas of China are the typhoon prone areas. In the history, there experienced many typhoons, such as "dispute resolution", "cimaron", "tam mei", "Mr", "matmo", "sudie" and so on. These typhoons are responsible for the collapse and destroy of a large number of houses, in addition to the damages of houses; they also caused great damage to things along the way, such as trees, billboards, etc. (Figure 1). Obviously, the devastating typhoons can cause enormous economic loss.

In order to further study the disaster situation of coastal village buildings affected by typhoons, authors of the paper had carried on the on-the-spot investigations of coastal areas. Through in-depth investigations and studies, the building damage situation and failure mechanis $m$ are summarized and analyzed. Based on the investigation results, some suggestions on planning construction and structural measures are proposed, which will be beneficial to wind resistance of the coastal towns housing.

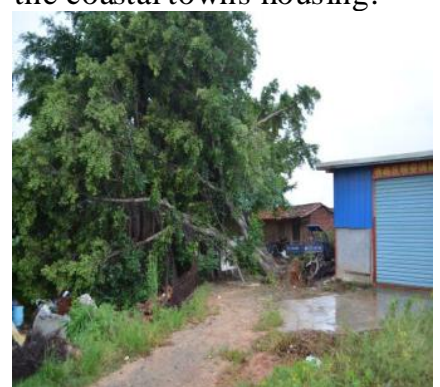

(a) The trees blown down by the wind

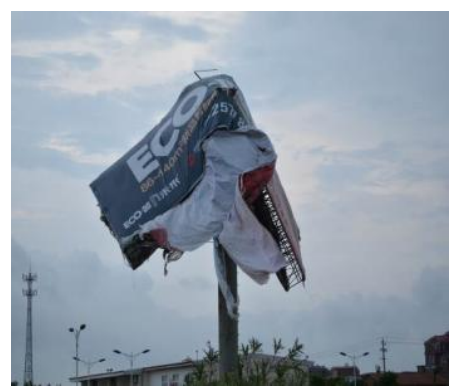

(b) The damaged billboard blown by the wind
Figure 1 . The damage items of roadside caused by the typhoon

\section{BUILDING DAMAGE OF DISASTER AREAS}

\section{A. Wooden Frame Buildings}

The wooden frame buildings are mostly old houses with only one or two stories, which use the wooden skeleton as load-bearing elements and packed earth or adobe masonry as the enclosing walls mostly. The wooden frame is integrated by tenons with weak connections in both longitudinal and lateral directions. Some houses are set a timber between stories, without columns throng stories (Figure 2). The column feet of wooden frame of some houses are directly put on the bricks or stone foundation with the absence of reliable connection. There is no connection between retaining wall and timber frame without forming a solid entirety, and the integrity of the wall itself is rather bad. Additionally, structure aging and disrepair lead to the damage of retaining wall (Figure 3), mortise connection failure (figure 4), loadbearing wood skeleton tilting or even collapse. 


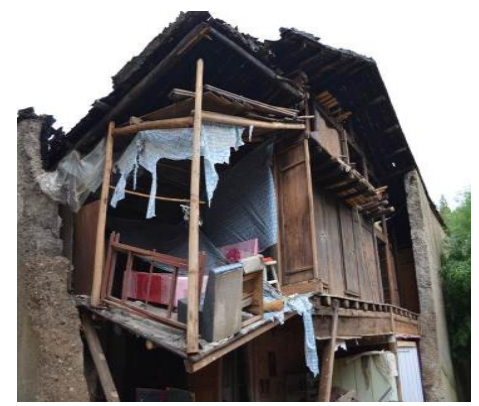

Figure 2. The disconnected columns bet ween stories of building

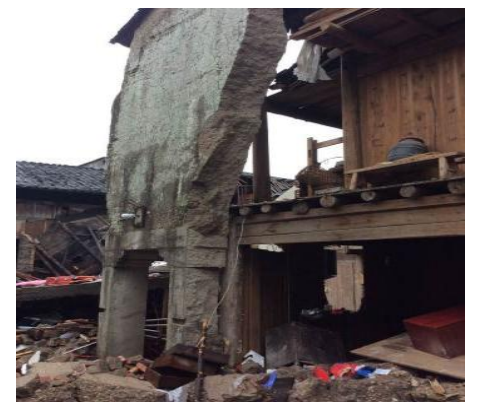

Figure 3. The damage of wall in wooden structural house

\section{B. Raw-soil Structures}

Raw-soil structures employ earth walls as the main bearing system, with wooden purlines setting on the earth walls, rafters laying on purlines, and Chinese style tile roof placed on the rafters. [1] The putting of wooden purlines simply on the wall leads to their lack of rigid connection with walls, and Chinese style tile roof having light weight, both cause raw soil structure buildings easy to damage by the wind. What's more, the strength and bearing capacity of the earth walls will drop sharply after a long time washing and infiltrating of the rain, combined with the destruction of the typhoon, the walls collapse, as shown in figure 5. When the walls are damaged, the whole building will lose the bearing capacity and finally collapse. Most of the massive collapsed buildings caused by the typhoon are raw-soil houses.

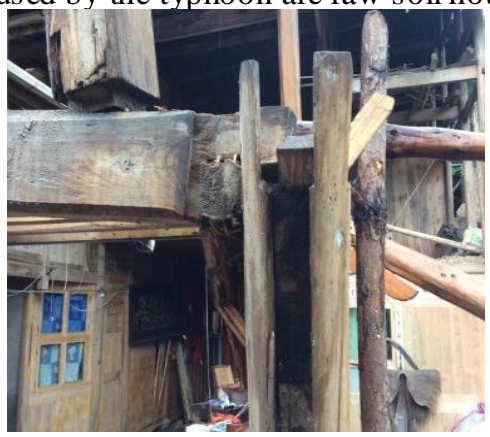

Figure 4. The damage of tenon connection in wooden structure

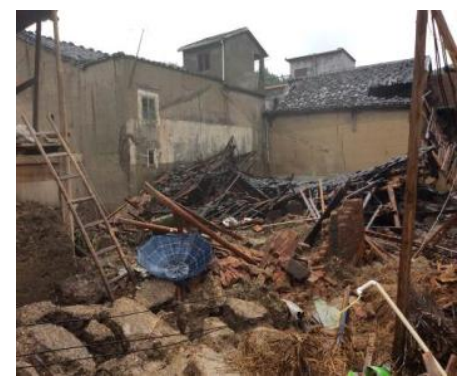

Figure 5. The collapse of raw-soil house

\section{Brick-wood Buildings}

In the low brick-wood structures of coastal areas, the brick walls play the role of bearing, the building roofs are still consist of timber purlins and Chinese style tiles. Because the timber purlins are simply put on the walls, which lack reliable rigid link with vertical wall, the buckling out-of-plane will occur between the house roofs and vertical walls, and the house roofs can't play roles of effective control. ${ }^{[1]}$ Chinese style tiles in the typhoon often fall into the wind, thus the pulling force between roof purlins and vertical walls will almost completely lose. Combined with walls within each story uses the method that a bucket to build by laying bricks or stones, without taking construction measures that using constructional columns and rachel tendons between the vertical and horizontal walls, thus the integrity is also very poor. Furthermore, the intensity of external walls gradually decreases without taking any protective measures or mortar body as well as the long-term exposure to natural weathering erosion, eventually the walls collapse in the typhoon, and the roofs subside.

\section{Stone Masonry Buildings}

As shown in Figure 6, stone masonry houses are mostly single story structures, this kind of buildings were built earlier but have better ability to resist wind. The loadbearing walls and foundation of stone masonry houses are all made of stones, the walls have very high bearing capacity and shear strength; The slope of the building roof is smaller, the purlins end are put into the walls inside deeply, the purlins and walls constraints reciprocally to strengthen the connection between each other. The adoption of densely covered small red tile roofs, as well as using mortar materials as the binder between roofs and tiles can ensure the integrity of roofs. A lot of bricks are put above the red tiles, which provides a certain protective effect to the roofs. In the typhoon, such buildings damage is mainly in the form that there is lack of effective connection between roof tiles or roof coverings and purlines or roof truss, leading to the blown away of tiles by typhoon, but other parts of build ings are in good condition basically and have no damage. 


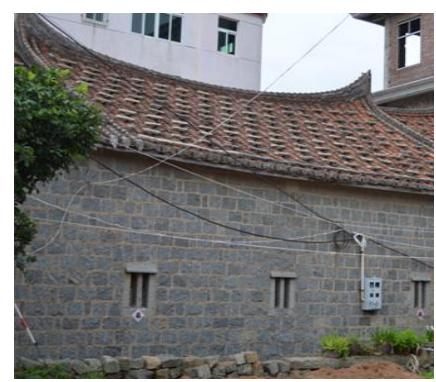

Figure 6 . The basically int act stone

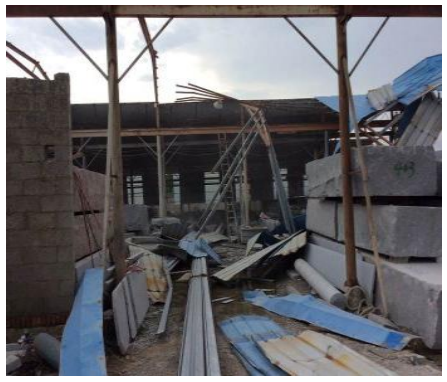

Figure7. The damage of steel masonry building roof truss

\section{E. Steel Structure Buildings}

In the coastal rural areas, some industrial factory buildings adopt steel structure systems, for this type of structures, mainly the light steel roofs and roof truss are destructed under the effect of typhoons. Figure 7 shows a stone processing plant, the structure is simple, no walls, and roofs are some thin light steel plates. Because there are no fences, the typhoons will make the different pressures between the top roofs and bottom ones, which exert a lot of pulling force upwards on the roofs. Besides, the junction between the light steel plates laying on the roofs and the lower main structures is not strong enough; causing the roof panels blown down and roof truss damaged (Figure 7).

\section{F. Other Types of Buildings}

In addition to the above structures, there are also some other types of buildings, such as concrete frame buildings, brick-concrete structure buildings, etc.. However, these types of houses in the typhoons almost have no damage phenomenon. Ring beams are set up both in the concrete frame buildings and brick-concrete structure buildings, which make the stiffness and integrity of the buildings improved greatly. The angle setting constructional columns of the concrete frame houses also make the build ing form a unified whole. Meanwhile, the cast-in-place concrete roofs also replace the conventional Chinese style tile roofs, thus reducing wind-induced damages to the roofs. The wind resisting ability of these types of houses is better; the damage caused by the typhoons is not obvious, as shown in Figure 8.

Although the structure systems of the concrete frame structure and brick-concrete structure houses in the typhoons suffer little damage, many roofs are the slope roofs hanging tiles. In the typhoons, many slope roof tiles are blown away by the typhoons, after a typhoon, the villagers will repair the housing roofs in such damaging forms timely (Figure 9).

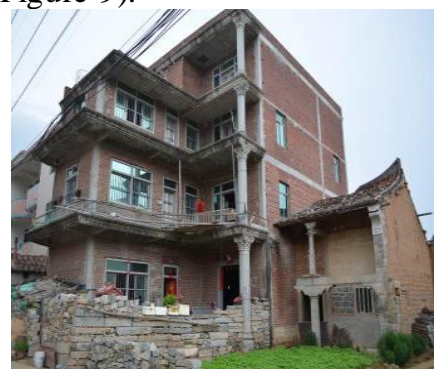

Figure 8 . The basically int act concrete frame building

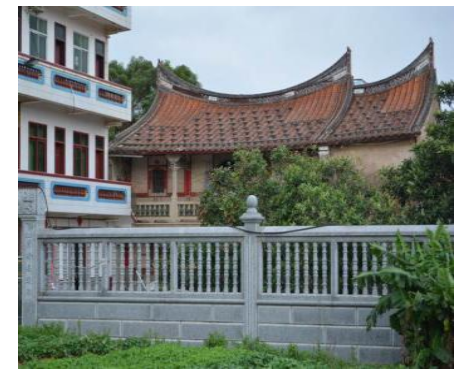

Figure 9. The tiles of house roof blown away (Have been repaired)

\section{G. Summary to Building Damage}

By comparing the housing damage in typhoons, it can be found that the structures of the buildings are mainly wood structures and civil structures in the less developed areas, the quality of buildings is poor, and housing damage is serious. However, in the relatively developed areas, the housing quality is better, and the defensive measures are more comprehensive, thus the building damage can be less serious. But the houses destroyed in the cyclone have common characteristics in structure, namely: Chinese style tile roofs, poor integrity, small stiffness, structure aging, weak joint, and longitudinally without resistance to lateral force system and so on.

From the building damage, it can also be found that the destruction of the houses in the typhoons is not just attributed to the wind load. After the typhoon landing, continuous torrential rain follows, and the heavy storm can cause geological disasters such as mudslides and landslides, which can also make the villagers' houses in low-ly ing areas suffered from floods. The secondary disasters such as floods and mud-rock flows have strong destructive power; the damage is devastating and should be avoided as far as possible. If the houses are exposed to a long- term rain soaking and floods scouring, their strength and bearing capacity will drop sharply, leading to the house collapse, it is also a problem that should be considered in the design.

\section{THE PROBLEMS EXIST ING IN THE HOUSING CONST RUCT ION OF COAST AL TOWNS}

The typhoons caused enormous damage to the low houses in coastal villages and towns, which is not only attributed to the powerful typhoon action and its secondary disasters, the structures of the local buildings and the 
building process also exist some problems summarized as follows:

(1) A large number of local low-rise buildings, especially the houses mainly composed of brick-wood structures; the building geometry is adverse to wind resistance and exsits big problems. The height-width ratio and length-width ratio of these buildings are relatively great, and the story height is too big, besides, these buildings usually lack longitudinal walls support. The bearing walls stability is poor, and the windward area is large, which is easy to be damaged for happening instability in the typhoons. In addition, the shear strength and stiffness of some build ing roofs and walls is not enough, the setting of ring beams and constructional columns is improper, [2] or even without the ring beams and constructional columns, which can also cause the buildings serious damage.

(2) As rural construction most uses local materials, the material quality is difficult to guarantee, bringing some hidden troubles to the housing quality; The mortar strength is not up to standard, and the lime content is bigger, the intensity will greatly reduce after the rain soaking, which can weaken the shear capacity of the walls; In building construction, the construction personnel are not trained, most rely on their old experience, so the construction quality is difficult to guarantee without the careful design and calculation as well as the formal design drawings. [2]

(3) The location of some houses is improper. Many houses in low-lying areas, which are vulnerable to be attacked by the typhoons and floods at the same time; There are also some houses in the open fields or valleys, which are easy to suffer from the front strong attack of typhoons; Some houses are located in geological hazards area, making the housings easy to damage and collapse due to the typhoons attack against the main body and the heavy floods destruction to the basis.

(4) In many undeveloped villages and towns, in order to save building cost, the villagers use the cheap building materials such as raw soil to build the exterior walls. After the completion of houses, no measures are taken to protect the exterior walls. The walls strength will decrease for exposing to the air for a long time, especially when the typhoons come, the walls bearing capacity will greatly reduce because of the heavy rains washing and soaking, making the walls damage in the typhoons, thus leading to the roofs collapse and even greater damage.

(5) So me villagers randomly add stories, build walls, open holes and change the uses to the finished houses without scientific guidance, and change the building structure features or increasing load unreasonably [2], which makes the houses in danger all the time and the safety of residents cannot be ensured.

\section{SUGGEST IONS ON WIND RESIST ANCE PLANNING CONST RUCT ION AND CONST RUCTION MEASURES FOR THE COAST AL TOWNS BUILDINGS}

\section{A. Suggestions on Wind Resistance Planning Construction for the Coastal Towns Buildings}

According to the above problems found in the field investigations, several aspects of planning construction suggestions are proposed for the low houses in coastal villages and towns: [3]

(1) In the choice of housing planning location, try not to select the wind outlet, mountain pass and river mouth areas that are adverse to wind resistance, as well as not to select the unstable slopes or landslides, flash floods and mudslides threatened regions which can pose a direct threat on the site stability to construct houses.

(2) The houses try not to adopt scatter construction, and avoid locating outside of the towns and villages or becoming isolated houses, so as to avoid the typhoons positive effect and enhancing the strong building destructions caused by typhoons.

(3) The commencement date and construction schedule should be planned reasonably to avoid leaving unfinished or just completed buildings during typhoon seasons, which are easier to damage under the typhoons effect.

(4) Appropriate building sizes are very important to enhance the buildings ability to resist the typhoons, so the buildings length-width ratio, height-width ratio, story height and roof forms and so on should be optimized reasonably. At the same time, low housing shapes should be distributed symmetrically, too high stories are unfavorable, generally not more than four stories to avoid a single house protruding from the surrounding houses, becoming the primary brunt objects by the typhoons, and bring disasters to the surrounding houses.

\section{B. Suggestions on Construction Measures for the Coastal Towns Buildings}

According to the buildings failure mechanis $m$ in the typhoons, we can adopt corresponding countermeasures and construction measures to improve the buildings wind resistance ability, in order to ensure the security of people's lives and property. To enhance the integrity and stiffness of the houses can improve the wind resistance performance. Under the influence of the typhoons, to strengthen the connections between each component of low houses and improve the integrity of the structures are very important to boost the buildings wind resistance ability. In the fieldworks, it is also learned that the damages and collapses of quite a number of houses are due to their insufficient integral rigidity, so increasing the stiffness of the structures can also improve the wind resistance ability of low houses. Meanwhile, adding some structural measures can also improve the wind resistance capability of the buildings to a certain extent. Below some measures are summarized respectively to improve the housings integrity, stiffness and strength, as well as some construction measures to set up on the roofs. 


\section{1) Measures to improve the housing integrity [4]:}

a) Enhance the integrity of the roofing system:

Taking measures to strengthen the connection and support between the roof board or roof tiles and purlines, purlines and purlines, purlines and roof truss, and to improve the roofing integrity, thus avoiding a portion of the roof being destroyed easily in the typhoons, and making the roofing system become a solid whole.

b) Strengthen the connection between the roofing system and its bearing structures:

For the less deadweight roofing systems, the roofing lift force caused by typhoons is sometimes greater than the roofs deadweight, so that the joints of roofs and walls will generate tension, which easily leads to the overall upward displacement and collapse of the roofs.

c) Reinforce the connection between the wall itself, the walls and ring beams, the walls and constructional columns:

The external walls of the low houses will be directly affected by the typhoons large lateral horizontal wind load, so their strength and stability are very important. In order to enhance the strength and stability of the walls, we can design the ring beams and constructional colu mns, and the walls should be reliably connected with the ring beams, in addition, the intervals of the outer walls constructional columns should not be too large, the area of the single block wall between the constructional columns and ring beams also should not be too large, which can guarantee the integrity and stability of the walls.

d) Ensure the reliable delivery of wind load:

The force transferring path of low-rise housing wind load is "wind load-roofing-purlines-roof-roof truss-load bearing walls -foundation",[5] only ensuring the continuous reliability of this path, and passing all the upper force to the foundation, the safety of upper structures and the integrity of whole house can be guaranteed.

2) Measures to ensure the stiffness and strength of structures [4]:

- Control height-thickness ratioof the walls, guarantee the stability of the walls and try not to use hollow walls;

- Set constructional columns in the weak structure positions such as the four corners of external walls, the junction of vertical walls and cross walls, and the both sides of larger holes;

- Set ring beams in each story of the masonry buildings, the corners, windows, doors and holes location should be solidly built by laying bricks or stones according to the construction requirements;

- Try to use the concrete cast-in-site plates and porous plates that have good integrity and horizontal stiffness as the floors;

- Take measures to prevent water and mo isture in the building corners and foundation of the low-lying areas, and keep off the walls intensity reducing under the water immersion, which can finally lead to the walls destruction and collapse;
- Use the qualified construction materials in quality and intensity to increase the structure stiffness of buildings.

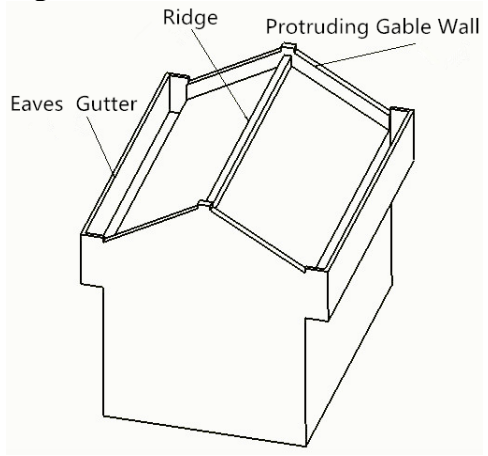

Figure 10. The schematic diagram of roof detail structure

\section{3) Roofing construction measures:}

From the field investigations, it can be found that the damage and collapse of low-rise houses more begins with the destruction of the roofs in the typhoons. Except for the insufficient roof strength and the unstable connection with the lower structures, another reason why the roofs are vulnerable to damage under the effect of typhoons is that the roof geometry shape have many mutation positions, such as eaves, corners, roof, and roof ridges, while the airflow goes through, it often produces the flow separation and reattachment phenomena, the wind suction is big and change dramatically. For this case, we can set up some detail structures on the roofs to reduce the damage, as shown in figure 10 .

- Set mountain ridge and deyama. The combined function of mountain ridge and deyama can greatly reduce the wind load of roofs, compared to the roofs without mountain ridge and deyama, the roofs with mountain ridge and deyama have unique advantages in decreasing the roof lifting force and the peak negative pressure of sensitive areas. [6]

- Add cantilever parapet. Adding cantilever parapet around the eaves can lower the high negative pressure peak and average wind suction, achieving the purpose of reducing wind load for the roofs. [7]

- Set overhangs and rone can also improve the wind resistant ability of roofs to a certain extent. [8]

- In the low buildings wind resistance study, professor Peng Xingqian from Huaqiao University proposed the wind resistance concept based on the aerodynamic measures, and the concept pointed out that replacing "wind resistance design" with "ventilation design", replacing "resistance" with "guide" for short. [9] To be specific, not to pursuit the roof strength too much to resist strong wind, but take some aerodynamic measures like setting the cantilever parapets, housing chamfers and deflector holes (open holes) to unmount the strong wind, and reduce the wind load effect on the structures.

In addition to the above structural measures, it is also an effective measure to develop the energy dissipation 
elements suitable for the roofs based on the structural vibration control technology, such as damping energy dissipation and wind resistance devices, etc., which can protect the roofing systems from damage in the typhoons.

\section{CONCLUSIONS}

Through the studies and analysis for the rural houses disasters and wind resistance situation caused by the typhoons in China coastal areas, the following conclusions can be concluded:

(1) The common features of the houses destroyed in the typhoons are: Chinese style tile roofs, poor integrity, s mall stiffness, structure aging, and weak connection, vertical without resistance systems and so on.

(2) Most good wind resistance houses were built not for a long time, the upper parts are mainly frameworks or brick structures, and the roofs are mainly concrete cast-in-place slabs; However, the most buildings with poor ability to resist wind were built early, the upper parts are primarily wooden structures, raw soil structures, brick-wood structures or brick-concrete structures with poor structural measures, and the roofs are mostly Chinese style tile roofs.

(3) It can be found that, in addition to the case that the incorrect sizes lead to the damage of structure trunks, the the destruction of the low-rise houses more begins with the roofs damage in the typhoons, thus resulting in the damage of the walls, and even the overall collapse of build ings.

(4) The destruction of the houses is not just the single function of the typhoons, the secondary disasters such as the rainfalls brought by the typhoons also have strong destructive power, while improving the ability to resist the wind, and some measures should also be taken to prvent the damage of the buildings caused by other secondary dis asters.

(5) According to the damage of the buildings in the typhoons, some proposals are provided on the construction planning and construction measures of the rural houses in coastal areas. For the disaster areas that suffer from the typhoons frequently, the houses can be optimized according to these proposals to achieve the purpose of enhanceing the wind resistance abilityof build ings.

\section{ACKNOWLEDGMENT}

This works is supported by the National "12th Fiveyear" Plan for Science \& Technology Pillar Program (2014BA L05B03). Innovation Group Program of National Natural Sciences Foundation of China (51421064).

\section{REFERENCES}

[1] P. Huang, L. Tao, Y. Quan, M. Gu. Investigation of wind resistance performance of rural houses in coastal areas of Zhejiang Province [J].2010, 25 (4): 90-95,138.

[2] J. Yuan, Y. Zhan. Several suggestion on wind load resistance design base on Performance investigation of town buildings in Zhejiang province [J]. Architec -tural design and research instit ute of Zhejiang Province. 2008, 25 (12): 15-20.

[3] T. R. Zhang, J. G. Xiang, Y. H. Mao. Zhejiang southeast typhoon disaster mechanism analy sis the building. 2010, 36 (3): 86-89.

[4] Q. X. Zhao. Investigation of wind-resistant for low-rise buildings in southeast coastal areas [D]. Shanghai: Tongii University, 2007.

[5] F. Liang. Study on numerical simulation of wind pressure and windresistant design of low-rise buildings in China [D]. Tianjin: Hebei University of Technology, 2006.

[6] P. Huang, L. Tao, Y. Quan, M. Gu. Effect of ridge and protruding gable wall on wind loadings on low-rise buildings' roof [J]. Engineering Mechanics.2012, 29 (4): 113-121,127.

[7] X.P. Zhou. Influence to wind pressures on the roof of low-rise gableroofed buildings with cantilevered-parapets[D]. Quanzhou: Huaqiao University.2008.

[8] P. Huang, L. Tao, Y. Quan, M. Gu. Effect of eaves gutter on wind loadings on low-ri-se buildings' roofs [J]. Engineering Mechanics.2013,30 (1): 248-254.

[9] X. Q. Peng. Aerodynamic measures of low-rise buildings in windresistance design-Wind leading design research of portal frame buildings [D]. Shanghai: Tongji University. 2006. 9. 